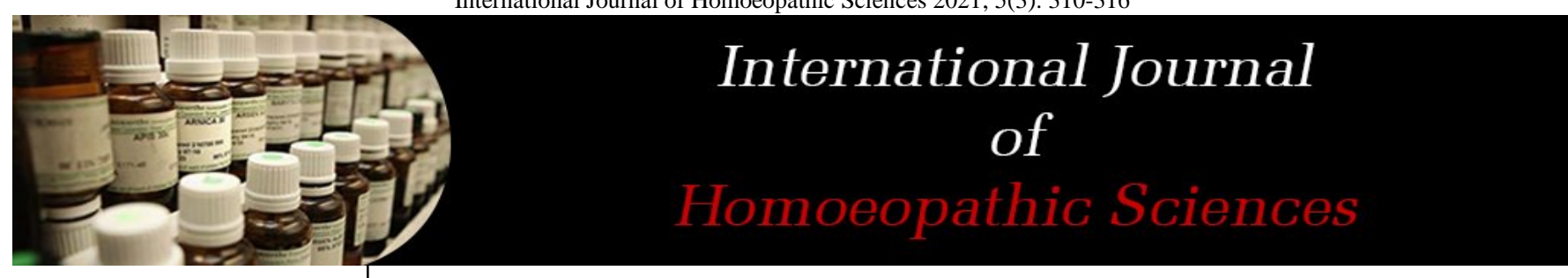

E-ISSN: $2616-4493$

P-ISSN: 2616-4485

www.homoeopathicjournal.com

IJHS 2021; 5(3): 310-316

Received: 08-05-202

Accepted: 10-06-2021

Dr. J Senthil Kumar

Professor, HOD and PG Guide,

Department of Repertory,

Vinayaka Mission's

Homoeopathic Medical College

\& Hospital (A Constitute

College of Vinayaka Mission's

Research Foundation -

Deemed to be university),

Salem, Tamil Nadu, India

Dr. M Alex Pandi

Associate Professor,

Department of Anatomy,

Shri Barani Homoeopathy

Medical College \& Hospital,

Pilikkalmedu, Tiruchengode,

Namakkal, Tamilnadu, India

Corresponding Author:

Dr. J Senthil Kumar

Professor, HOD and PG Guide,

Department of Repertory,

Vinayaka Mission's

Homoeopathic Medical College

\& Hospital (A Constitute

College of Vinayaka Mission's

Research Foundation -

Deemed to be university),

Salem, Tamil Nadu, India

\section{Clinical utility of Kent repertory in the homoeopathic management of renal calculi}

\section{Dr. J Senthil Kumar and Dr. M Alex Pandi}

DOI: https://doi.org/10.33545/26164485.2021.v5.i3e.440

\begin{abstract}
Stones disease is our orders crusade with severe morbidity. It is relatively a common disorder affecting 1 to 3 percent of adult in industrialized counties. Renal calculi are much more popular in males than in females in developed countries. $12 \%$ of males and $5 \%$ to $10 \%$ of females who are affected by kidney stones. The urinary calculi increases with age, many usual in the in the age of 30 - 50 age. After the age 60 period, the figure reduction and approaches figure by the ninth decade of the life. ${ }^{[1]}$ Renal calculus incidence in diametric countries varies depending on the areas environmental conditions. In India, the prevalence of Urolithiasias is higher compared to that of grey states in northern states. Renal calculi are many oft seen in warmer climate and summer. Therefore this research to understand the in Kent repertory much useful for the treatment of renal calculi it give a group of remedy which are efficacious in the handling of renal calculi.
\end{abstract}

Keywords: Homoeopathy, renal calculi, Kent Repertory

\section{Introduction}

A renal calculus is a highly prevalent condition with rate of recurrence is high that has a major effect on the quality of life for the affected persons. It also a great financial burden on society the surgery for renal calculi because the cost is high with various associated risks.

1. So need a simple a simplex. Value potent. Painless blood treatment. Which not exclusive remove the calculi, but also helps in removing way for calculi manufacture. Now a day's Homoeopathy is play a vital role in the management of renal calculi and helping in treating the without surgery, and the refrain of inherent, antimiasmatic solutions is often used to discourage recurrences.

\section{Epidemiology:}

Urinary calculus is really the third most serious urinary system disorder, afterward only urinary system infection and cervix pathological circumstances. A number of disciplines are responsible for the nomenclature linked with urinary stone. ${ }^{[2]}$

Stone disease is more common in northern India due to various etiopathological factors prevailing there. The trends are changing in southern India. This may be due to changes in socioeconomic or dietary pattern of the population consequent to the emigration to the gulf countries. Urinary stone is commonly seen in the age group of 20 to 50 years. $90 \%$ of the stone patients are males in India. After 50 years it is equitant in both age group because of androgen more menopausal women. This is more common among sedentary life style Higher incidences of stone disease are noted in summer months ${ }^{[3]}$. A recurrence rate of around 20 percent is reported each year; the first pier former has a $40 \%$ chance of further measurement within 5 years ${ }^{[4]}$.

\section{Clinical Features}

Types of renal calculi ${ }^{[5]}$

Primary Calculi - are those that occur without any antecedent inflammation in perfectly normal tract. These stones are commonly produced in the urine of acid. The stones are normally calcium oxalate, uric acid, urate, cystine, Xanthine, or calcium carbonate \& Struvite Stones

Secondary Calculi is triggered by Infection. Urine is typically alkaline since the most common causative species are the separating urea species. 
The supplementary stones are primarily made of ammonium-magnesium phosphate (three phosphates allegedly). The structure of supplementary stones can include amorphous phosphates and ammonium urate. Phosphate stones are most of the supplementary stones.

\section{Signs and symptoms ${ }^{[6]}$}

- Fixed renal pain

- Ureteric colic

- Hydronephrosis

- Fever

- Sweating

- Nausea and Vomiting

- Haematuria

- Oliguria

- Dysuria

\section{Objectives of the study}

To study the efficacy of the Homoeopathic medicines in the management of Renal calculi. To compare the efficacy homoeopathic medicines in the modulation of size of renal calculi, pre and post treatment by Ultrasonography.

Sample size was 30 in number, they were chosen depending on USG

\section{Materials and Methods source of data}

Patients will be collected from the in-patent and outpatient departments, peripheral centers, rural health camps and medic call camps conducted by Vinayaka mission's Homoeopathic Medical College Hospital,

Patient selected on the basis of inclusion criteria, history and Clinical Symptoms. Totality formed on basis of Homoeopathic Kentian concept. Prescription based on the totality of case by using Repertory of homoeopathic Materia medica by Kent. But the study was limited and the medicine selected within the preview of the review of literature.

Patients admitted in the IPD for investigation and probable diagnosis, later on the case were followed in OPD for a period of 12 months, every case was followed according to the case.

\section{Prognostic criteria}

- Basing symptomatic improvement and Compare Ultrasonography findings before and after the treatment.

\section{Inclusion Criteria}

- Renal calculi patients of both sexes between 20-60 age groups.

\section{Exclusion Criteria}

- Staghorn stones,

- Renal stone associated with renal transplantation

- Patients with skeletal abnormalities either congenital or acquired.

- Medullary sponge kidney (MDK)

- Renal tubular acidosis

- Renal stone associated with tumors

- Caliceal diverticula

- Renal malformation

\section{Homoeopathic regulation}

- The patients were measured, examined and evaluated by Kentian approach.
- It was done by using Kent’s repertory.

- Selection remedy - a solution by Kentian method and Indicated medicine was prescribed in medium potency.

- After the administration of one dose of selected medicine patient was kept under observation in order to see the response of the medicine.

- The second prescription was made depend upon the response of the first prescription. If the symptoms or recurrent or standstill the case need next potency of the same medicine was administered.

- The prognosis was recorded every fifteen days with mental generals, physical generals, and characteristic particulars.

\section{Results and finding}

Table 1: Age wise distribution of renal calculi

\begin{tabular}{|c|c|c|c|}
\hline S. No. & Age Groups (in years) & No. of Patients & Percentage \\
\hline 1. & $20-30$ & 7 & $23.33 \%$ \\
\hline 2. & $31-40$ & 8 & $26.6 \%$ \\
\hline 3. & $41-50$ & 10 & $33.33 \%$ \\
\hline 4. & $51-60$ & 5 & $16.6 \%$ \\
\hline & Total & 30 & $100 \%$ \\
\hline
\end{tabular}

Table shows, out of 30 cases selected for the study, maximum prevalence of renal calculi 10 cases were seen in the age group above $40-50$ years.

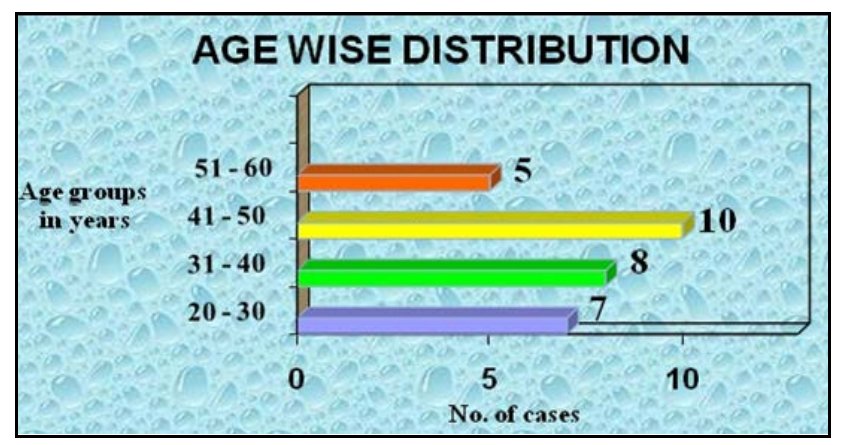

Fig 1: Bar - diagrammatic representations of age wise distribution of renalcalculi

Table 2: Sex wise distribution of renal calculi

\begin{tabular}{|c|c|c|c|}
\hline S. No. & Sex & No. of patients & Percentage \\
\hline 1. & Male & 18 & $60 \%$ \\
\hline 2. & Female & 12 & $40 \%$ \\
\hline & Total & 30 & $100 \%$ \\
\hline
\end{tabular}

Table shows, out of 30 cases selected for the study, 18 cases (60\%) were males and 12 cases (40\%) were females. Males are affected more than females.

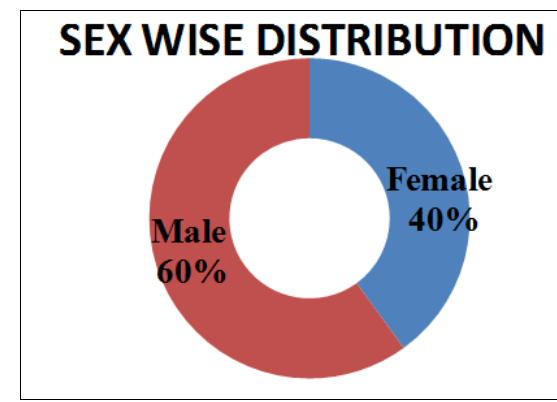

Fig 2: doughnut - diagrammatic representation of Sex wise distribution of renal calculi 
Table 3: Distribution of occupation.

\begin{tabular}{|c|c|c|c|}
\hline S. No. & Occupation & No. of Cases & Percentage \\
\hline 1. & Human Recourses & 1 & $3.33 \%$ \\
\hline 2. & House Wife & 5 & $16.68 \%$ \\
\hline 3. & Carpenter & 1 & $3.3 \%$ \\
\hline 4. & Weaver & 3 & $10 \%$ \\
\hline 5. & Driver & 2 & $6.68 \%$ \\
\hline 6. & Sweeper & 1 & $3.33 \%$ \\
\hline 7. & Business & 3 & $10 \%$ \\
\hline 8. & Salesman & 2 & $2.68 \%$ \\
\hline 9. & Coolie & 3 & $10 \%$ \\
\hline 10. & Students & 2 & $13.33 \%$ \\
\hline 11. & Farmer & 2 & $6.68 \%$ \\
\hline 12. & Supervisor & 1 & $6.68 \%$ \\
\hline 13. & Teacher & 30 & $3.33 \%$ \\
\hline & Total & & $100 \%$ \\
\hline
\end{tabular}

Table shows, most of the patients were house wife 16.6\%). Students (13.33\%), Weaver (13\%) were significantly involved.

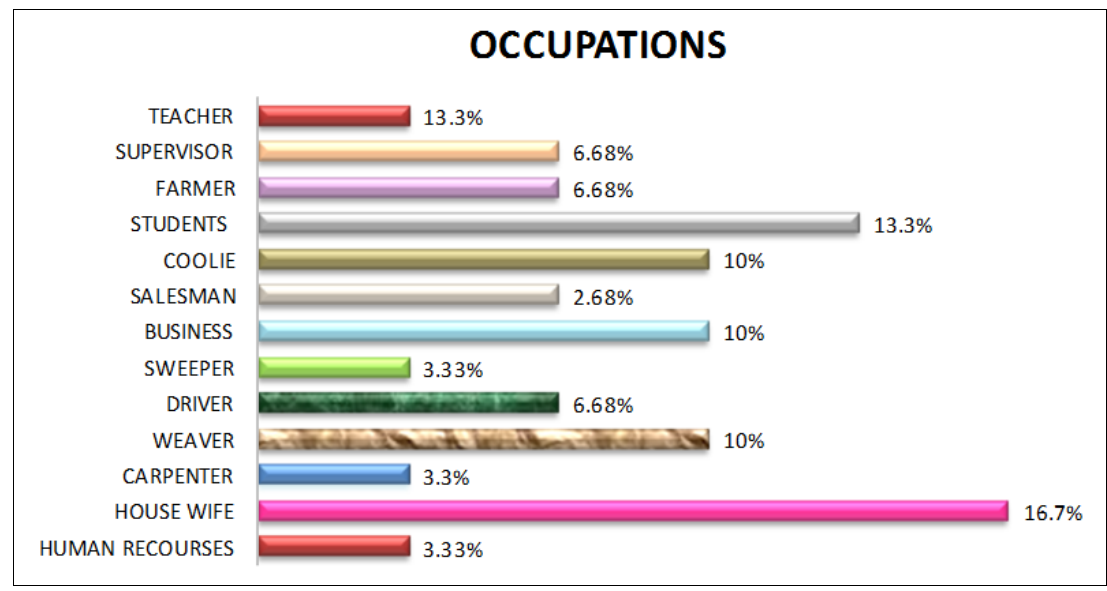

Fig 3: Bar - diagrammatic representation of distribution of occupations

Table 4: Distribution of presenting complaints of renal calculi

\begin{tabular}{|c|c|c|c|}
\hline S.No. & Presenting complaints & No. of cases & Percentage \\
\hline 1. & Pain in loin only & 2 & $6.7 \%$ \\
\hline 2. & Pain with frequent urination & 4 & $13.3 \%$ \\
\hline 3. & Pain with burning urination & 10 & $33.3 \%$ \\
\hline 4. & Pain with dysuria & 8 & $26.7 \%$ \\
\hline 5. & Pain with nausea and vomiting & 4 & $13.3 \%$ \\
\hline 6. & Pain with Bloody urine & 2 & $6.7 \%$ \\
\hline & Total & 30 & $100 \%$ \\
\hline
\end{tabular}

Table shows that pain with burning urination (33.3\%) and Pain with dysuria (26.7\%), Pain with frequent urination and
Pain with nausea vomiting (13.3\%) were the most common presenting symptoms seen in renal calculi patients.

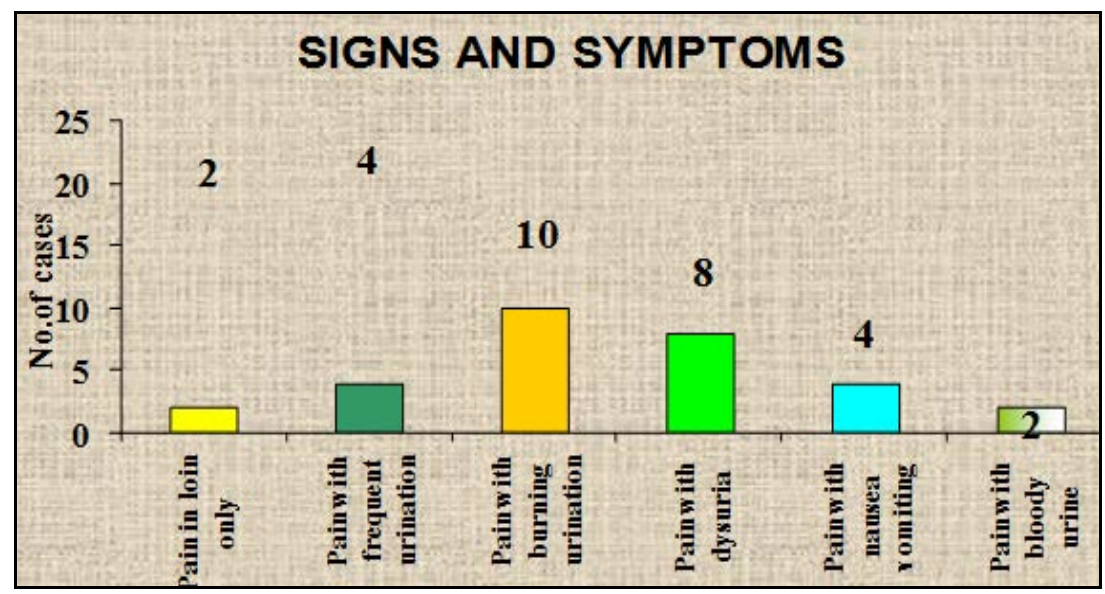

Fig 4: Column - diagrammatic representation of distribution of signs and symptoms of renal calculi. 
Table 5: Distribution of side affinity to renal calculi

\begin{tabular}{|c|c|c|c|}
\hline S. No. & Diet & No. of patients & Percentage \\
\hline 1. & Right side & 7 & $23.3 \%$ \\
\hline 2. & Left side & 10 & $33.3 \%$ \\
\hline 3. & Bilateral & 13 & $43.4 \%$ \\
\hline 4. & Total & 30 & $100 \%$ \\
\hline
\end{tabular}

Table shows, that the majority of patients suffering from bilateral Renal calculi 13 cases (43.4\%), left side renal calculi has 10 cases (33.3\%), and right side had 7 cases $(23.3 \%)$. So when most of the patients are suffer from bilateral renal calculi.

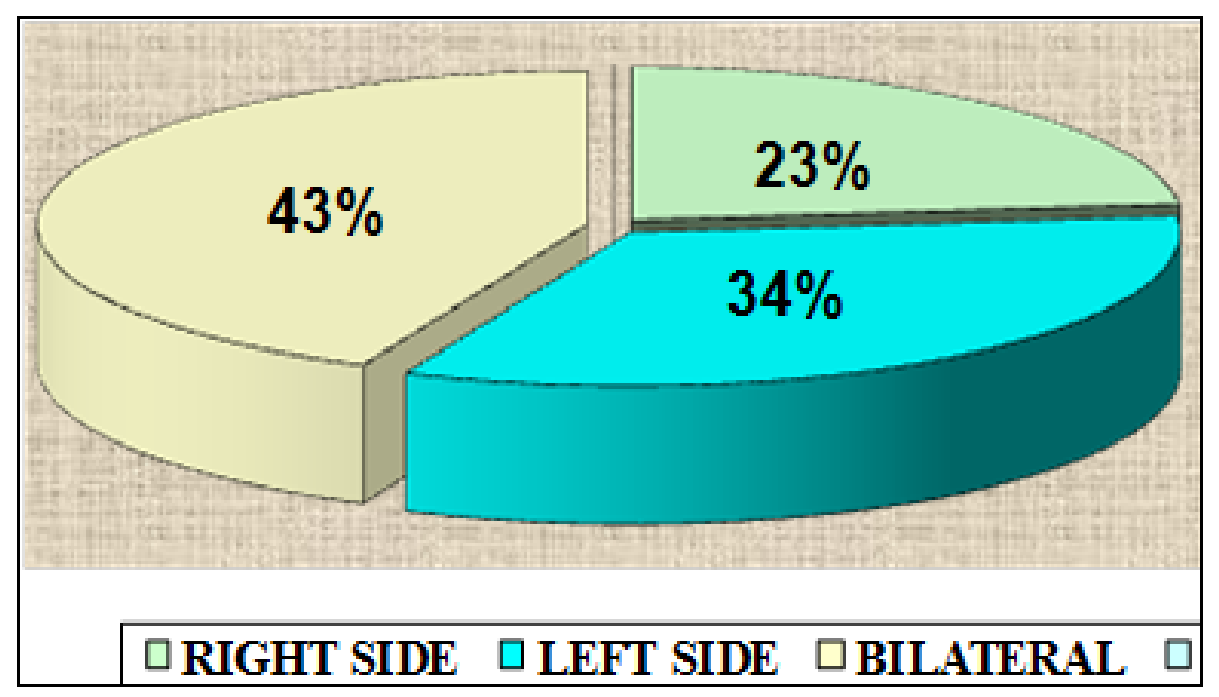

Fig 5: Pie - Diagrammatic Representation of Distribution of Side Affinity of Renal Calculi

Table 6: Distributions of patients based on fundamental miasm.

\begin{tabular}{|c|c|c|c|}
\hline S. No & Fundamental miasm & No. of cases & Percentage \\
\hline 1. & Psora & 5 & $16.6 \%$ \\
\hline 2. & Sycosis & 23 & $76.7 \%$ \\
\hline 3. & Psorosycotic & 2 & $6.7 \%$ \\
\hline & Total & 30 & $100 \%$ \\
\hline
\end{tabular}

Table shows 23 cases (76.7\%) have Sycotic as fundamental miasm. 5 cases $(16.6 \%)$ have psora as fundamental miasm.

2 cases $(6.7 \%)$ have Psorosycotic as fundamental miasm.

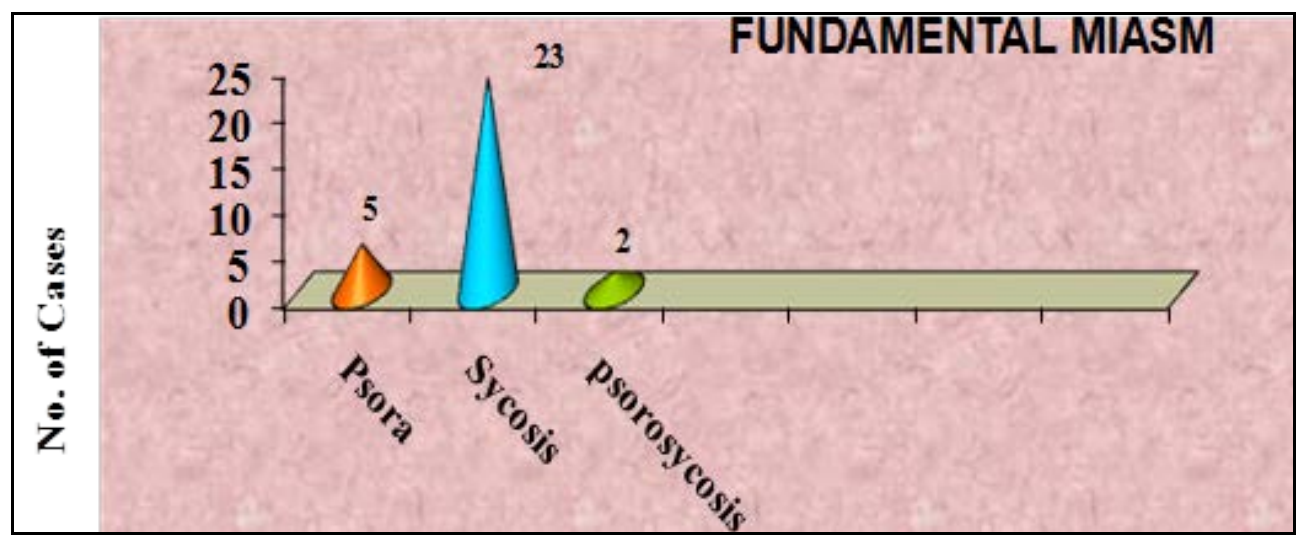

Fig 6: Column - diagrammatic representation of distribution of patients based on fundamental miasm

Table 7: Distribution of patients based on dominant miasm.

\begin{tabular}{|c|c|c|c|}
\hline S. No. & Dominant miasm & No. of cases & Percentage \\
\hline 1. & Psora & 10 & $33.3 \%$ \\
\hline 2. & Sycosis & 11 & $36.7 \%$ \\
\hline 3. & Syphilis & 1 & $3.3 \%$ \\
\hline 4. & Psorosycotic & 8 & $26.7 \%$ \\
\hline & Total & 30 & $100 \%$ \\
\hline
\end{tabular}

Table shows 11 cases (36.7\%) have Sycotic as dominant miasm. 10cases (33.3\%) have psora as dominant miasm. 1 cases (3.3\%) have syphilitic as dominant miasm. 8 cases (26.7\%) have Psorosycotic as dominant miasm. 


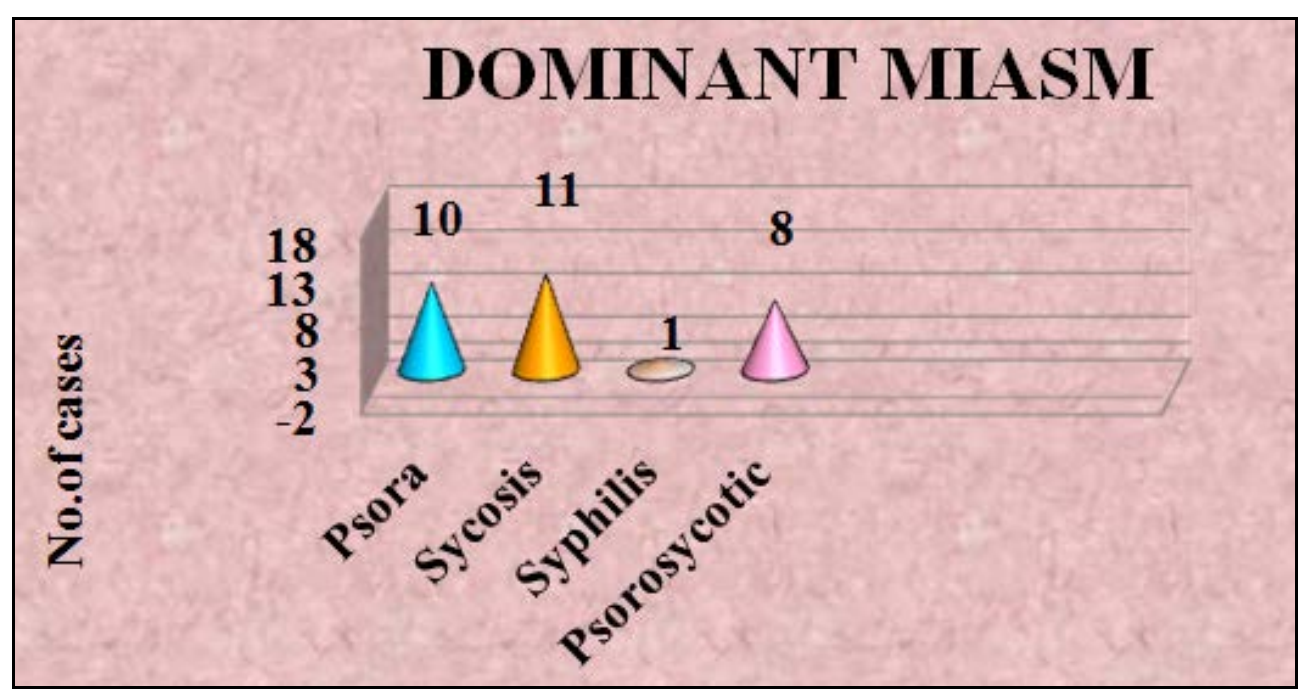

Fig 7: Column - diagrammatic representation of distribution of patients based on dominant miasm

Table 8: Distribution of patients based on acute remedies used.

\begin{tabular}{|c|c|c|c|}
\hline S. No & Acute remedy & No. of Cases & Percentage \\
\hline 1. & Hydrangea & 7 & $23.3 \%$ \\
\hline 2. & Berber vul & 5 & $16.7 \%$ \\
\hline 3. & Cantharides & 4 & $13.3 \%$ \\
\hline 4. & Sarsaparilla & 2 & $6.7 \%$ \\
\hline 5. & Apis mellifica & 1 & $3.3 \%$ \\
\hline 6. & Tabacum & 1 & $3.3 \%$ \\
\hline 7. & Solidago & 2 & $6.7 \%$ \\
\hline 8. & No remedy & 8 & $26.7 \%$ \\
\hline & Total & 30 & $100 \%$ \\
\hline
\end{tabular}

Table shows that 7cases (23.3\%) have used hydrangea, 5 cases (16.7\%) have used Berber vul, 4cases (13.3\%) have used Cantharides, 2 cases (6.7\%) have used sarsaparilla, 1case (3.3\%) have used Apis mel, 1case (3.3\%) have used Tabacum, 2cases (6.7\%) have used Solidago, 8 cases (26.7\%) have not used acute remedies for renal calculi.

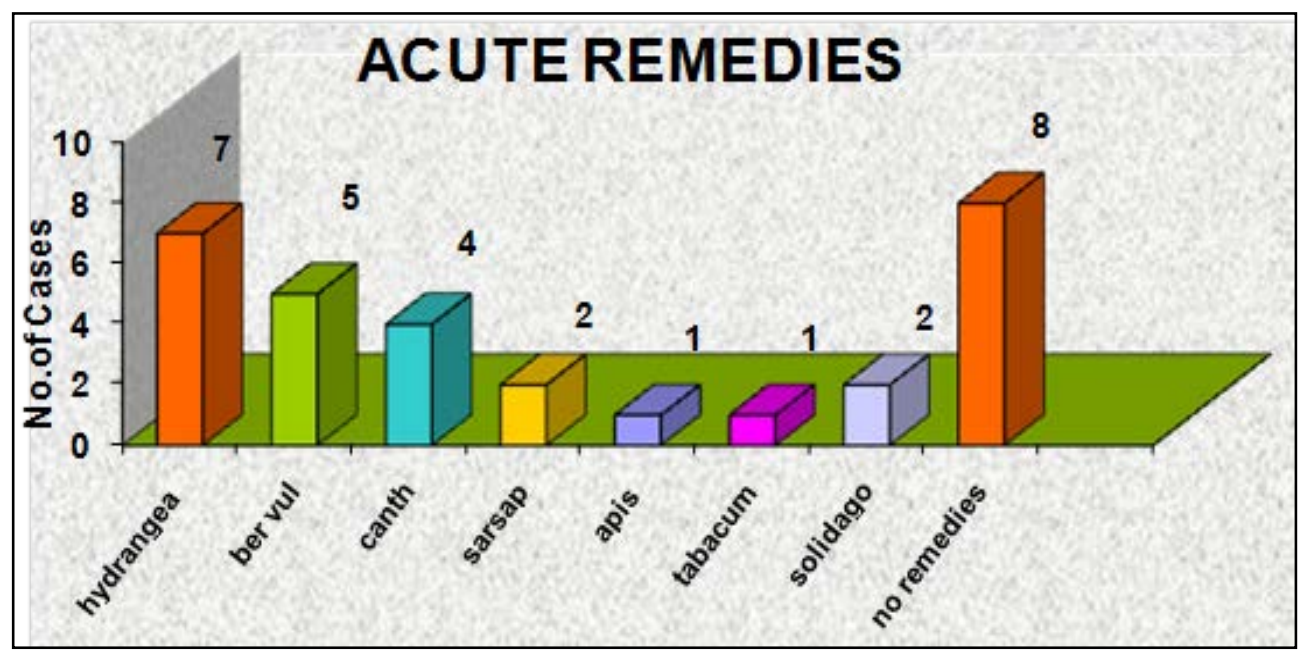

Fig 8: Column - diagrammatic representation of distribution of acute remedies in this study

Table 9: Distribution of patients based on constitutional remedies used.

\begin{tabular}{|c|c|c|c|}
\hline S. No & Constitutional remedy & No. of Cases & Percentage \\
\hline 1. & Nux vomica & 8 & $26.7 \%$ \\
\hline 2. & Lycopodium & 6 & $20 \%$ \\
\hline 3. & Calcarea carbonicum & 5 & $16.6 \%$ \\
\hline 4. & Sulphur & 4 & $13.3 \%$ \\
\hline 5. & Natrum Muriaticum & 2 & $6.7 \%$ \\
\hline 6. & Pulsatilla & 2 & $6.7 \%$ \\
\hline 7. & Cantharides & 2 & $6.7 \%$ \\
\hline 8. & Sepia & 1 & $3.3 \%$ \\
\hline & Total & 30 & $100 \%$ \\
\hline
\end{tabular}


Table shows that Nux vomica (26.7\%) and Lycopodium (20\%) were frequently indicated as constitutional remedies for renal calculi. Next to this Calc carb, Sulphur, Natrum Muriaticum, Pulsatilla, Cantharides, Sepia are indicated.

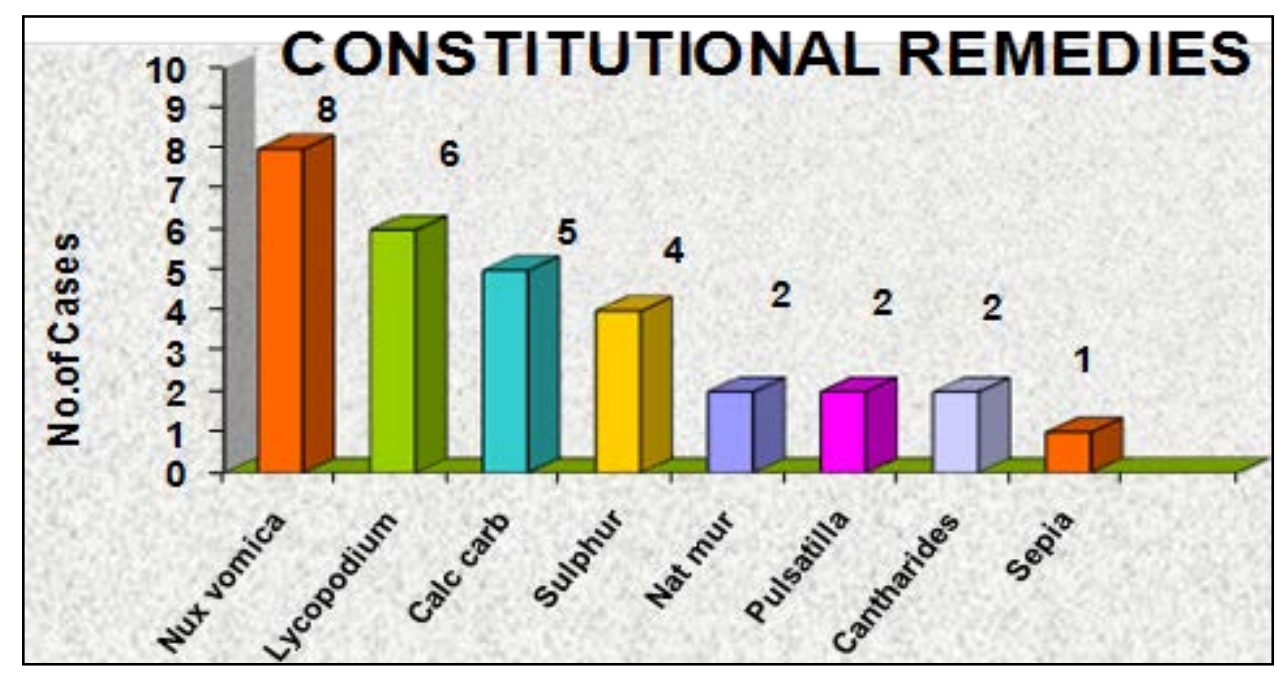

Fig 9: Column - diagrammatic representation of distribution of constitutional remedies

Table 10: Distribution of patients based on inter current remedy used.

\begin{tabular}{|c|c|c|c|}
\hline S. No & Remedy & No. of Cases & Percentage \\
\hline 1. & Inter current remedy used & 22 & $73.3 \%$ \\
\hline 2. & Inter current remedy not used & 8 & $26.7 \%$ \\
\hline & Total & 30 & $100 \%$ \\
\hline
\end{tabular}

Table shows that 22 cases (73.3\%) has given inter current remedies, 8 cases (26.7\%) has not given inter current remedies.

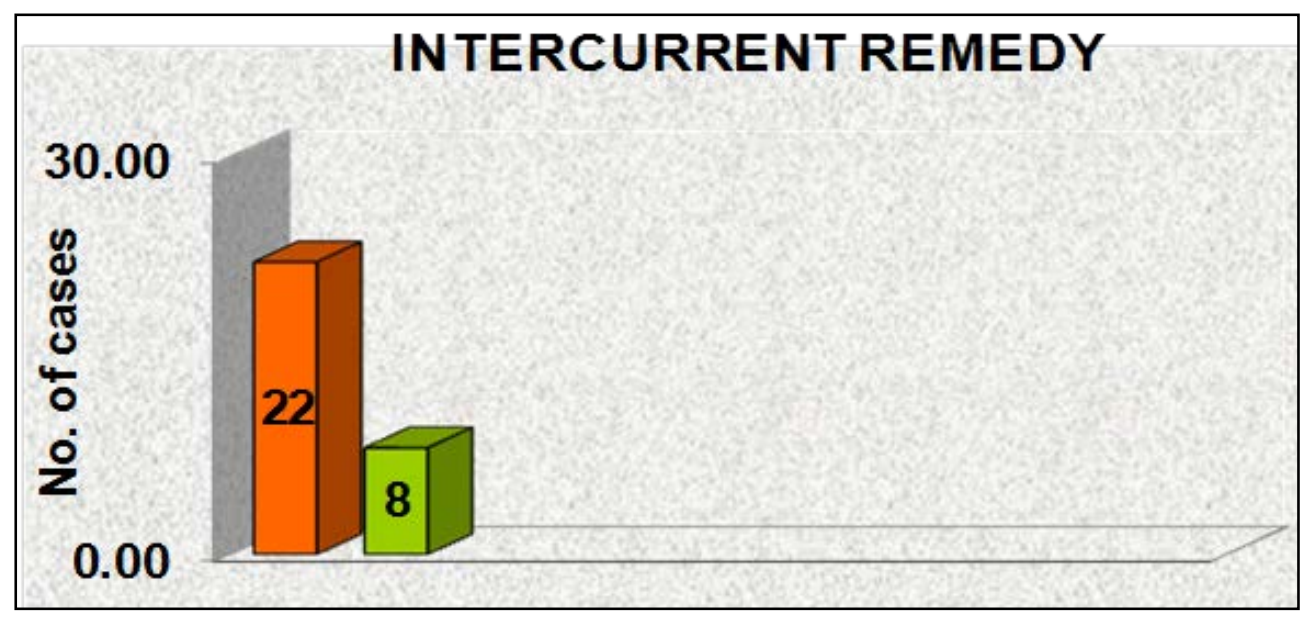

Fig 10: Diagrammed representation of distribution of inter current remedy in this study

Table 11: Distributions of results of homoeopathic treatment of renal calculi.

\begin{tabular}{|c|c|c|c|}
\hline S.no & Result & No. of patients & Percentage \\
\hline 1. & Relieved & 13 & $43.3 \%$ \\
\hline 2. & Marked improvement & 5 & $16.7 \%$ \\
\hline 3. & Moderate improvement & 6 & $20 \%$ \\
\hline 4. & Mild improvement & 4 & $13.3 \%$ \\
\hline 5. & No improvement & 2 & $6.7 \%$ \\
\hline & Total & 30 & $100 \%$ \\
\hline
\end{tabular}

Table shows, out of 30 cases, 13 cases (43.3\%) were Cured and 5 cases $(16.7 \%)$ had shown Marked improvement, 6cases (20\%) moderate improvement, 4 cases (13.3\%) mild improvement, 2 cases $(6.7 \%)$ has no improvement. 


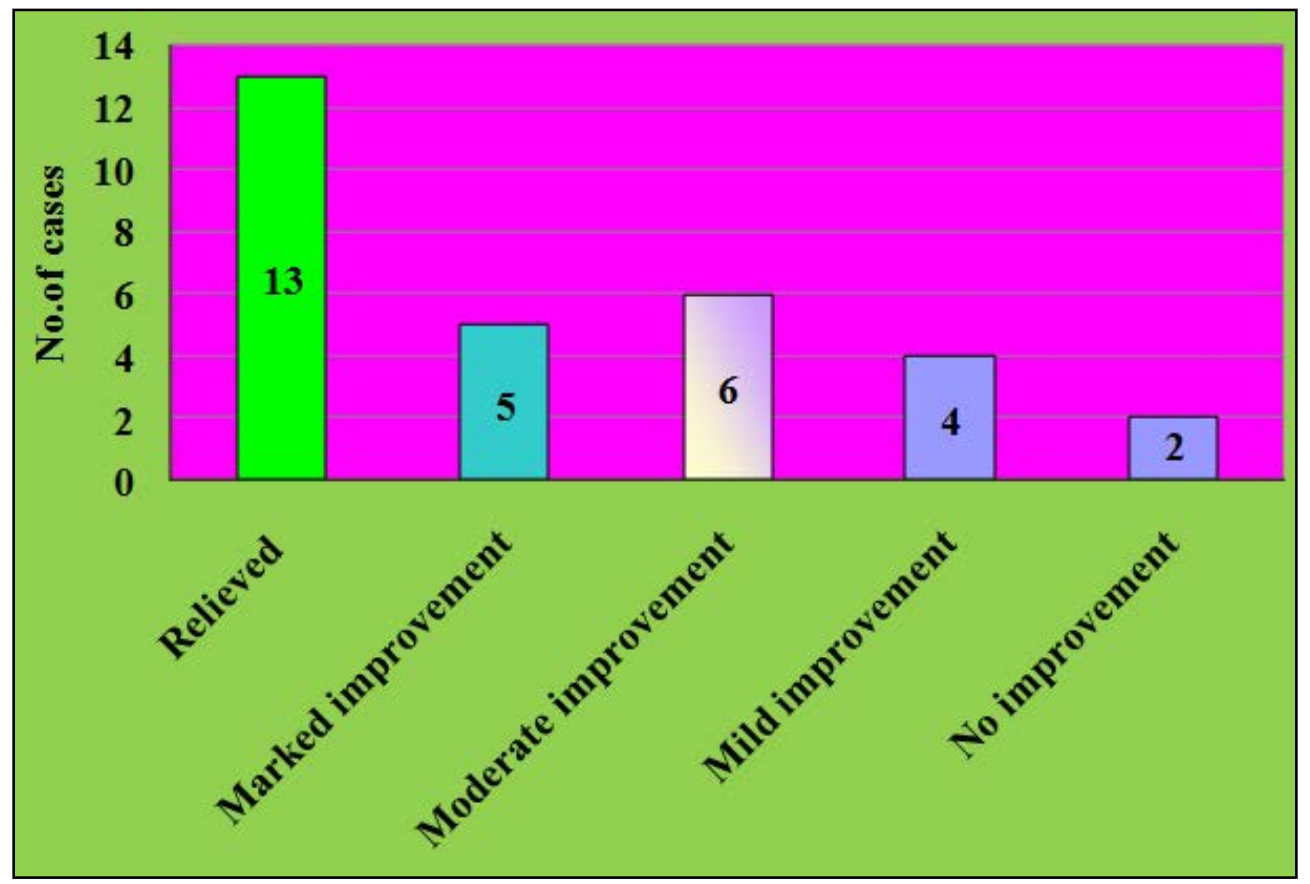

Fig 11: Diagrammatic Representation of Distribution of Results of Homoeopathic Treatment

\section{Summary and Conclusion}

Thirty cases of Renal Calculi were taken into consideration for the study. The patients were between the age group of 20 - 60 years. Patients of both sexes were treated. A detailed case history with the proper clinical examination was done in all the patients. The medicine was given after repertorising in repertory of homoeopathic materia by Kent. The commonly affected age group according to my study was $41-50$ years (33.33\%). Males 18 cases $(60 \%)$ are affected more than females 12 cases (40\%) were evidence by this study shows. As far as side affinity of suffering from bilateral Renal calculi 13 cases (43.4\%), left side renal calculi has 10 cases (33.3\%), and right side had 7 cases (23.3\%). So when most of the patients are suffer from bilateral renal calculi. Sycotic played is maims of both fundamental and dominant miasm. Lycopodiums, Hydrangea, Nux vomica were found to be most frequent indicated medicines for my studies. Most of the patient got cured (43.3\%) from their complaints some patients (16.7\%) shows marked improvement (16.7\%), (20\%) cases shows moderate improvement and (13.3\%) showed mild improvement, 2cases (6.7\%) has no improvement. My study provides evidence to say that, there is significant improvement in renal calculi patients after giving homoeopathic treatment with Kent repertory.

\section{Reference}

1. Schwartz Shires Spencher. Principles of surgery, $6^{\text {th }}$ international edition, 1743.

2. Smith's. General Urology by Smith's, $14^{\text {th }}$ international edition, 276-290.

3. Salam EMA. Principles o\& practice of surgery $2^{\text {nd }}$ edition volume -2 by E.MA. Salam, Jaypee brothers medical publishers (p) Ltd 2013, 543-553.

4. Disease monograph. 5 Urolithiasias - CCRH New Delhi 2011, 85. Camphell - walsh urology ninth edition volume two, by wein, Kavoussi, Novick, Partin, peters Pg.no-1434-1434.(1373,(1363-1392)

5. Das S. A Manual On Clinical Surgery, $5^{\text {th }}$ edition, S. Das publications, 335-381.
6. Dennis Kasper L. Eugene Braunwald, Anthony S. Fauci, Stephen Hauser L, Dan Longo L, Larry J. Harrison's Principles of Internal Medicine, $16^{\text {th }}$ edition, McGraw - Hill Medical Publishing Division, 1710-24, 2.

7. Kumar and Clark clinical medicine $6^{\text {th }}$ edition 2005, ISBN Publishers, 648 to 653.

8. Bakshi JPS. Manual of urogenital disorders", India, Cosmic Healus Pvt. Ltd 2002, 293-349.

9. Dr Lai Chiu-Nan. Removing Kidney stone Naturally, (http://forumhub.com/southfood/15301.3956.02.58.21.h tml)

10. Sarkar BK. Hahnemann's Organon of Medicine with an Introduction and Commentary on Text, Calcutta: $\mathrm{M}$. Bhattacharyya \& Co Pvt. Ltd, 8th Indian Edition, Reprint 1987.

11. Http://Www.Similima.Com, Urolithiasis and homoeopathic management

12. Hahnenann CFS. Organon of Medicine, New Delhi: B. Jain Publisher Pvt. Ltd, 6th Edition.

13. Allen JH. "The chronic miasm psora and pseudopsora" Vol I \& II. B Jain publishers, PVT limited, New Delhi 1994.

14. Chakarvarthy BN. 'Renal disorders; Homoeopathic heritage; jan 2000, 10-12

15. Tiwari SK. Essentials of Repertorisation, III revised \& enlarged edition 2003, B. Jain Publishers Pvt Ltd.

16. Dr. Munir Ahamed R. Introduction to the Principles of Repertorization, Reprint Edition, Books \& Allied (P) Ltd 2001.

17. Kent JT. Repertory of Homoeopathic Materia Medica, Enriched Indian Edition. B. Jain Publishers (P) Ltd 2014. 